\begin{tabular}{|c|c|c|}
\hline $\begin{array}{l}\text { PKS } \\
\text { PUBLIC } \\
\text { KNOWLEDGE } \\
\text { PROSECT }\end{array}$ & $\begin{array}{c}\text { REVISTA DE GEOGRAFIA } \\
\text { (RECIFE) } \\
\text { hitp://www.revistaupe.brrevistageografia }\end{array}$ & $\begin{array}{l}\text { OJS } \\
\text { OPEN } \\
\text { JOPNALA } \\
\text { SYTESMS }\end{array}$ \\
\hline
\end{tabular}

\title{
OLIGOPOLIZAÇÃO E FINANCEIRIZAÇÃO DO SETOR SUCROENERGÉTICO BRASILEIRO NO SÉCULO XXI ${ }^{1}$
}

\author{
Henrique Faria dos Santos $^{1}$ \\ ${ }^{1}$ Doutorando e mestre em Geografia / Instituto de Geociências / Universidade Estadual de Campinas \\ (UNICAMP). E-mail: livehenriquefariasantos@hotmail.com. \\ Artigo recebido em 20/10/2017 e aceito em 03/02/2018

\begin{abstract}
RESUMO
O objetivo desse artigo é discutir o processo de oligopolização e financeirização do setor sucroenergético brasileiro ocorrido nos últimos anos sob a ótica da organização corporativa das grandes empresas e sob o paradigma produtivo da agricultura científica globalizada. O aumento das Fusões, Aquisições \& Associações (joint-ventures) de grupos nacionais e transnacionais com agroindústrias sucroenergéticas e tradings, especialmente após a crise econômica e financeira internacional de 2007-2008, demonstra um relativo movimento de concentração e centralização do capital na atividade canavieira. A inserção do setor sucroenergético aos parâmetros produtivos e comerciais de âmbito internacional reforça o uso estratégico do território pelas grandes corporações mundiais.
\end{abstract} \\ Palavras-chave: Setor sucroenergético, Oligopolização, Financeirização, Uso do Território.
}

\section{OLIGOPOLIZATION AND FINANCIALIZATION OF BRAZILIAN SUGARCANE SECTOR IN THE 21ST CENTURY}

\begin{abstract}
The objective of this article it is to promote a discussion of the recent oligopolization and financialization process of the Brazilian sugarcane sector, analyzing corporate organization of production of the major companies within the economic productive logic of scientific and globalized agriculture. The increase of mergers, acquisitions and associations (joint-ventures) of transnational and national corporations with sugarcane industries and tradings, especially after the global economic crisis of 2007-2008, shows a relative centralization and concentration of capital. The insertion of Brazil's sugarcane industry into international patterns of production and commercialization strengthens the strategic use of Brazilian territory by large globalized corporations.
\end{abstract} Keywords: Sugarcane Sector, Oligopolization, Financialization, Use of Territory.

\footnotetext{
${ }^{1}$ Artigo produzido a partir de pesquisa financiada pela Fundação de Amparo à Pesquisa do Estado de São Paulo (FAPESP). 


\section{INTRODUÇÃO}

A partir da primeira década do século XXI, o Brasil vivenciou uma grande expansão do setor sucroenergético, motivada por vários fatores internos e externos. No âmbito interno, a emergência dos veículos flexfuel (veículos bicombustíveis, ou seja, movidos tanto a gasolina quanto a etanol hidratado, em qualquer proporção) no mercado automobilístico, e o aumento da taxa de mistura do etanol anidro à gasolina de $20 \%$ para $27 \%$ entre 2001 e 2015 , foram os principais fatores responsáveis pelo aquecimento do mercado de biocombustíveis a base de cana-de-açúcar no país. A prática da cogeração de energia elétrica nas unidades agroindustriais sucroenergéticas (UAS) e a comercialização do excedente para o Sistema Interligado Nacional (SIN) tem sido também outro fator de forte atração de investimentos no setor canavieiro (NEVES; CONEJERO, 2010).

No âmbito externo, os mandatos de mistura de etanol anidro à gasolina em vários países do mundo e o próprio consumo do etanol hidratado em algumas nações (REN21, 2015), objetivando cumprir acordos firmados no Protocolo de Kyoto (redução de Gases de Efeito Estufa - GEE) e garantir maior segurança energética frente aos derivados do petróleo, abriu grandes perspectivas para a commoditização desse combustível (CGEE, 2009). Além disso, a gradativa valorização do açúcar nos mercados internacionais ao longo da década de 2000 contribuiu para o crescimento e liderança do Brasil na produção e exportação dos subprodutos da cana-de-açúcar (açúcar e etanol) (MAPA, 2015). Segundo a UNICADATA (2016), a área plantada de cana-de-açúcar no país saltou de 4,8 milhões para 10,8 milhões de hectares entre 2000 e 2015.

Nesse contexto, grandes corporações nacionais e transnacionais aumentaram sua presença no setor sucroenergético, mediante investimentos em Fusões \& Aquisições (F\&A), implantação de novos empreendimentos, ampliação e modernização de outros, e adoção de sistemas científico-tecnológicos nos segmentos agrícola e industrial, etc., o que significou a formação de grandes grupos e a eliminação de várias empresas menos capitalizadas no mercado. O maior controle do setor por um número menor de grupos econômicos altamente capitalizados e financeirizados evidencia processos de oligopolização e financeirização do complexo sucroenergético, sobretudo a partir da crise econômica e financeira internacional de 2007-2008 (MENDONÇA; PITTA; XAVIER, 2012). Como a instalação e operacionalização de UAS e centros logísticos demandam vultuosos aportes de capital, a tendência é a de que 
grandes grupos financeirizados liderem as atividades no setor, o que torna a atividade canavieira muito vulnerável à concentração e centralização de capital.

A consolidação do setor sucroenergético dependeu também da fundamental atuação do Estado, que por meio de um pacto federativo para a economia competitiva do agronegócio (DELGADO, 2012), tem estabelecido várias políticas de âmbito fiscal (redução ou isenção de tributos para o etanol e para as UAS, subsídios), financeiro (empréstimos principalmente do Banco Nacional de Desenvolvimento Econômico e Social - BNDES, seguro safra), comercial (elevação da taxa de mistura de etanol anidro à gasolina, aumento dos preços da gasolina, acordos de comércio exterior), normativa (leis, programas e projetos de fomento), tecnológica (PD\&I em instituições públicas, formação de mão de obra qualificada), infraestrutural (obras logísticas de armazenamento e transporte), entre outras, para estimular a organização e os novos investimentos privados (CGEE, 2009; DORNELLES, 2013).

Portanto, o presente artigo pretende discutir o processo de oligopolização e financeirização do setor sucroenergético na ótica da concentração e centralização do capital, que ganhou força sobretudo a partir do início século XXI. O aumento das operações de Fusões, Aquisições \& Associações com empresas menos competitivas do setor tem representado a constituição de um oligopólio no mercado de etanol e açúcar, privilegiando os agentes mais capitalizados. A financeirização dos agentes produtivos e do mercado subordina o setor a ditames internacionais de riscos e decisões dos principais investidores financeiros, uma vez que os grupos econômicos têm buscado no endividamento a formula para sustentar a expansão dos investimentos e a valorização dos seus ativos.

A metodologia da pesquisa consistiu em dois procedimentos: i) levantamento $e$ revisão bibliográfica (livros, artigos, teses e dissertações) sobre a expansão e conjuntura atual do setor sucroenergético, o movimento de concentração e centralização do capital na economia, as principais operações de fusões, aquisições e associações entre as grandes empresas do setor, e o processo de financeirização dos agentes produtivos; ii) pesquisa estatístico-documental sobre o número de operações de $\mathrm{F} \& \mathrm{~A}$ no setor sucroenergético entre 2000 e 2015 (Anuário do KPMG), a participação dos maiores grupos do setor na moagem de cana, produção e exportação de etanol e açúcar (Anuário da Cana 2016, NovaCana, Infocana, website das empresas), a participação das grandes distribuidoras nas vendas nacionais de etanol hidratado (ANP, 2016), os desembolsos do Banco Nacional de Desenvolvimento Econômico e Social (BNDES) para o setor sucroenergético (Informes BNDES), os principais grupos do setor com capital aberto na bolsa de valores (BM\&Bovespa, 2016) e algumas de 
suas estratégias corporativas. A sistematização desses dados teve como objetivo apurar o movimento de concentração do mercado de açúcar e etanol (produção e comercialização) e os principais grupos empresariais participantes desse processo, que passou a ser ainda mais intenso com a financeirização desses agentes nos últimos anos.

\section{O MOVIMENTO DE OLIGOPOLIZAÇÃO DO SETOR SUCROENERGÉTICO}

A desregulação estatal ocorrida no setor sucroenergético ao longo da década de 1990 e o aquecimento do mercado de etanol, açúcar e bioeletricidade pós anos 2000 atraiu diversas corporações nacionais e transnacionais altamente capitalizados e financeirizadas no setor sucroenergético. Estas corporações investiram na forma de fusões, aquisições, associações (joint-ventures) com unidades agroindustriais sucroenergéticas (UAS), distribuidoras de combustíveis, tradings e empresas logísticas, bem como a construção/criação de novas ou ampliação/modernização desses empreendimentos, a mecanização das operações agrícolas e a expansão geográfica das lavouras canavieiras (NEVES; CONEJERO, 2010; FAÇANHA, 2012). Esses eventos desencadearam, por sua vez, em processos de internacionalização (PINTO, 2011), oligopolização e financeirização do setor sucroenergético brasileiro (SPADOTTO, 2016; PITTA, 2016), acompanhando a mesma dinâmica de concentração e centralização do capital que tem ocorrido em outras atividades econômicas nacionais e internacionais, jus aos imperativos da globalização (HIRST; THOMPSON, 1998) e da neoliberalização internacional (HARVEY, 2011a).

Mas tais processos se intensificaram sobretudo após a crise econômica e financeira internacional de 2007-2008 (HARVEY, 2011b), que deixou muitas empresas nacionais do setor sucroenergético fragilizadas ${ }^{2}$ e vulneráveis à fusões e aquisições por grandes corporações (PITTA et al., 2014). A falta de crédito no mercado (custeio e investimentos), os endividamentos, a redução dos preços das commodities (como o açúcar) e o congelamento do preço da gasolina pelo governo brasileiro entre 2011 e 2015 (reduzindo possibilidades de aumento do etanol para suplantar custos mais elevados de produção) (PINHEIRO, 2015), deixaram muitas empresas a beira da falência. Nesse contexto, várias usinas fecharam e

\footnotetext{
${ }^{2}$ Pitta et al. (2014) explicam que diversas UAS tomaram empréstimos baratos em dólar (baixas taxas de juros nos EUA), aproveitando a valorização do real ao longo dos primeiros anos da década passada. Com a reversão dessa tendência e a valorização do dólar em relação à moeda brasileira na crise pós 2008, muitas usinas quebraram. Muitas empresas então deixaram de investir, por exemplo, na renovação de canaviais, tratos culturais e na adubação, o que diminuiu drasticamente a produtividade agrícola e a rentabilidade industrial, tornando muitas UAS brasileiras frágeis frente às instabilidades do mercado. 
muitas outras entraram em recuperação judicial (Gráfico 1), obrigando-as a colocarem os seus ativos à venda na tentativa de saldarem suas dívidas e/ou recuperar parte do capital perdido (MENDONÇA et al., 2012). Para Spadotto (2016), este contexto de crise contribuiu para "consolidar o setor sucroenergético", observando que:

[...] "não há nada melhor do que uma boa crise" para acirrar a competição capitalista, intensificar o movimento de centralização de capital (onde um capitalista expropria outro capitalista) e "consolidar" grupos hegemônicos no comando de determinado setor da economia (SPADOTTO, 2016, p. 71).

Gráfico 1 - Brasil: número de UAS implantadas, fechadas e reativadas e variação da capacidade instalada, 20052016

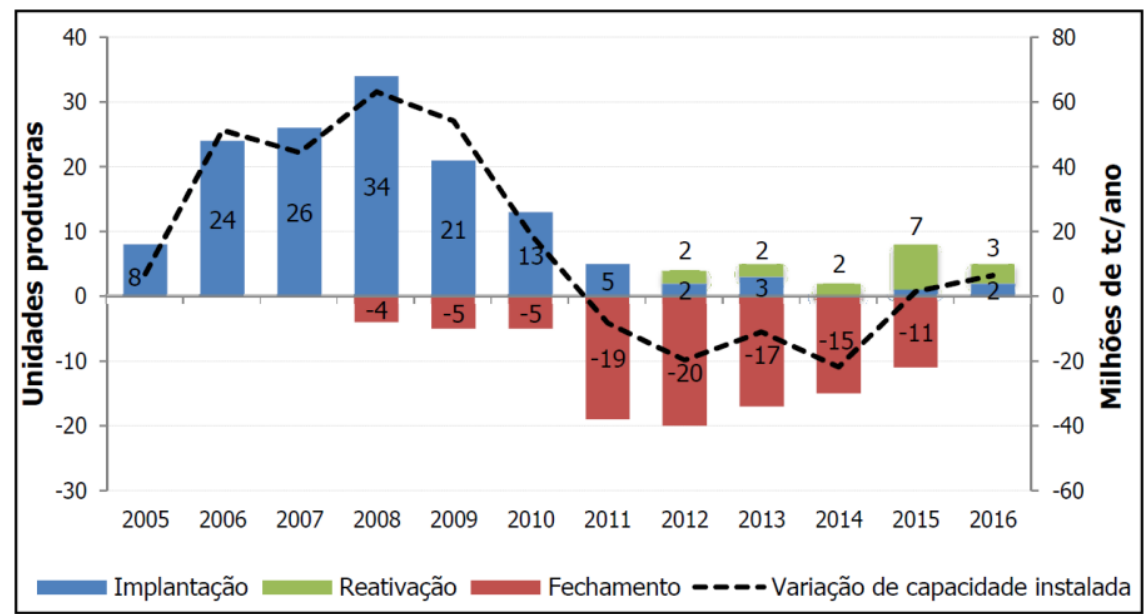

Fonte: EPE (2016, p. 29)

O movimento de concentração e centralização de capital remete a proposição de Marx (1980, p. 726). Para o autor, “ao ampliar-se a massa de riqueza que funciona como capital, a acumulação aumenta a concentração dessa riqueza nas mãos de capitalistas individuais e, em consequência, a base da produção em grande escala e dos métodos de produção especificamente capitalistas". Desta forma, "o crescimento do capital social realiza-se através do crescimento de muitos capitais individuais". Ou seja, o crescimento de vários grupos econômicos atuais levam à concentração de capital, em detrimento do aumento da desigualdade da distribuição da riqueza.

Já a centralização do capital caracteriza-se pela "transformação de muitos capitais pequenos em poucos capitais grandes". Conforme Marx (1980, p. 727) “o capital se acumula aqui nas mãos de um só porque escapou das mãos de muitos noutra parte. Esta é a centralização propriamente dita, que não se confunde com a acumulação e a concentração." 
Assim, processos de fusão, aquisição e associação e, consequentemente, oligopolização ${ }^{3}$, significam centralização de capital nas mãos de poucos grupos de grande porte. Porém, para Marx, a centralização é sempre acompanhada de concentração de capital, pois

[...] o progresso da acumulação aumenta a matéria que pode ser centralizada, isto é, os capitais individuais, enquanto a expansão da produção capitalista cria a necessidade social e os meios técnicos dessas gigantescas empresas industriais cuja viabilidade depende de uma prévia centralização do capital. Hoje em dia, portanto, é muito mais forte do que antes a atração recíproca dos capitais individuais e a tendência para a centralização (MARX, 1980, p. 728).

A internacionalização de uma atividade ou setor econômico é inclusive um dos fatores que podem levar à concentração e centralização do capital. No caso do setor sucroenergético, várias transnacionais do ramo do agronegócio, petróleo, química, financeiro, etc., realizaram F\&A com várias empresas brasileiras do setor, sobretudo com àquelas fragilizadas após a crise 2007-2008, resultando em forte concentração de capital. Tais empresas estrangeiras incluem as gigantes Louis Dreyfus Company (LDC), Bunge, Cargill, Tereos International, British Petroleum (BP Biofuels), Noble Group, Royal Dutch Shell, Shree Renuka, Glencore e Los Grobo (PINTO, 2011). Para Pitta et al. (2014), a intenção de várias dessas empresas é o de simplesmente aumentar o tamanho do capital a partir da diversificação e valorização de seus ativos, como máquinas, terras, unidades de produção agroindustrial, entre outros; com vista a obter maiores remessas de crédito junto às instituições financeiras para realizarem novos investimentos. Isto é fundamental, pois "a capacidade de uma empresa adquirir novas dívidas para continuar a investir em montantes mais elevados está atrelada ao seu tamanho, ou seja, aos valores dos seus ativos" (PITTA et al., 2014, p. 6).

Segundo dados da KPMG (2016), entre os anos 2000 e 2015 foram registradas 166 operações de F\&A no setor sucroenergético, sendo que mais da metade (90 operações) ocorreram a partir de 2008 (Gráfico 2). Essas operações foram realizadas, em boa parte, por corporações transnacionais, que passaram a investir no setor a partir de 2000 (Quadro 1). De acordo com Macêdo (2011), só entre 2008 e 2011, 59,8\% das principais operações de F\&A feitas no setor foram comandadas por corporações transnacionais, o que significou um

\footnotetext{
${ }^{3}$ Entendemos por oligopolização o processo pelo qual um setor ou atividade econômica se torna cada vez mais controlado por um número menor de empresas, ou seja, a constituição de um mercado oligopolizado na produção e/ou comercialização de algum bem ou serviço por poucos agentes, que passam a deter grande poder de mercado e, consequentemente, capacidade de impor preços e ofertas conforme interesses particulares às empresas. 
volume negociado de 104,5 milhões de toneladas de capacidade de moagem, com participação de empresas da Europa, EUA, China e Índia.

Gráfico 2 - Brasil: número de operações de fusões e aquisições no setor sucroenergético, 2000-2015

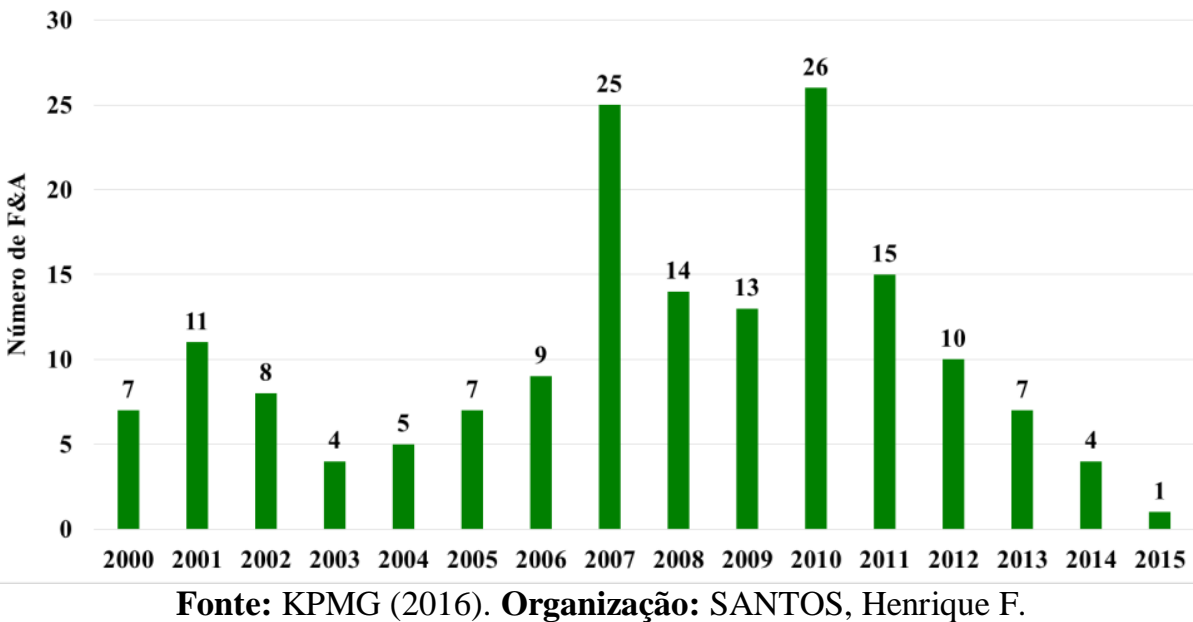

Quadro 1 - Brasil: relação de empresas estrangeiras que entraram como investidores diretos no setor sucroenergético, por ano de entrada, país de origem, setor principal de atuação e modo de entrada, 2000-2016

\begin{tabular}{|c|c|c|c|c|}
\hline Ano & Grupo & País de origem & Setor de origem & Modo de ent. \\
\hline 2000 & $\begin{array}{l}\text { LDC (Louis Dreyfus } \\
\text { Company) }\end{array}$ & França & Trading Company & Subsidiária \\
\hline 2000 & $\begin{array}{l}\text { Union DAS/Tereos } \\
\text { Internacional }\end{array}$ & França & Produção de açúcar & Joint-venture \\
\hline 2000 & Sucden & França & Trading Company & Joint-venture \\
\hline 2001 & Béghin-Say & França & Produção de açúcar & Subsidiária \\
\hline 2006 & Cargill & EUA & Trading Company & Joint-venture \\
\hline 2006 & Infinity Bio-energy & Brasil/EUA & Fundo de investimento & Subsidiária \\
\hline 2006 & Adecoagro & Argentina & Produção de grãos & Subsidiária \\
\hline 2006 & Colgua & Panamá & Produção de açúcar & Joint-venture \\
\hline 2006 & Clean Energy Brazil & Brasil/Inglaterra & Fundo de investimento & Joint-venture \\
\hline 2006 & CNAA & Brasil/EUA & Fundo de investimento & Joint-venture \\
\hline 2007 & Bunge & EUA & Trading Company & Subsidiária \\
\hline 2007 & Sojitz Corporation & Japão & Trading Company & Joint-venture \\
\hline 2007 & Noble Group & Hong Kong & Trading Company & Subsidiária \\
\hline 2007 & Abengoa Bioenergy & Espanha & Energia elétrica & Subsidiária \\
\hline 2007 & Dow Chemical Company & EUA & Químico e Petroquímico & Joint-venture \\
\hline 2007 & Brenco & Brasil/EUA & Fundo de investimento & Subsidiária \\
\hline 2008 & BP (British Petroleum) & Inglaterra & Petróleo & Joint-venture \\
\hline 2008 & $\begin{array}{l}\text { ADM (Archer Daniels } \\
\text { Midland) }\end{array}$ & EUA & Trading Company & Joint-venture \\
\hline 2008 & Amyris & EUA & Biotecnologia & Joint-venture \\
\hline 2008 & Itochu Corporation & Japão & Trading Company & Joint-venture \\
\hline 2008 & Mitsui Group & Japão & Trading Company & Joint-venture \\
\hline 2008 & $\begin{array}{l}\text { VREC (Vital Renewable } \\
\text { Energy Company) }\end{array}$ & $\begin{array}{c}\text { Brasil/EUA/ } \\
\text { Inglaterra/Bélgica }\end{array}$ & Fundo de investimento & Joint-venture \\
\hline 2009 & Shree Renuka & Índia & Produção de açúcar & Subsidiária \\
\hline 2010 & Glencore Xstrata & Suíça & Trading Company & Joint-venture \\
\hline 2011 & Los Grobo & Argentina & Produção de grãos & Joint-venture \\
\hline 2011 & Royal Dutch Shell & Holanda & Petróleo & Joint-venture \\
\hline 2013 & Indofood & Indonésia & Trading Company & Joint-venture \\
\hline 2016 & Somitomo Corporation & Japão & Trading Company & Joint-venture \\
\hline
\end{tabular}




\begin{tabular}{l|l|l|c|c}
2016 & Wilmar International & Singapura & Trading Company & Joint-venture \\
\hline
\end{tabular}

Fonte: PINTO (2011), atualizado pelo autor através do NOVACANA (2016) e JornalCana (2016)

A quantidade de F\&A presume então que o mercado sucroenergético (produção, distribuição e comercialização de etanol, açúcar e bioeletricidade) vem passando gradativamente por um processo de oligopolização, isto é, sendo controlado por um número cada vez menor de grupos econômicos altamente capitalizados e financeirizados, como é o caso dos grupos Copersucar, Raízen, Biosev, Odebrecht, São Martinho, Bunge, Tereos e Santa Terezinha (Tabela 1).

Tabela 1 - Controle acionário, número de UAS, capacidade de moagem, moagem de cana-de-açúcar, produção dos derivados (etanol, açúcar e bioeletricidade) e participação nacional, dos quinze maiores grupos do setor sucroenergético, safra 2015/2016

\begin{tabular}{|c|c|c|c|c|c|c|c|c|c|c|}
\hline \multicolumn{4}{|c|}{ Dados dos grupos } & \multicolumn{7}{|c|}{ Produção na safra 2015/2016 } \\
\hline Grupo & $\begin{array}{l}\text { Controle } \\
\text { acionário }\end{array}$ & $\begin{array}{l}\text { N. de } \\
\text { UAS } \\
(1)\end{array}$ & $\begin{array}{c}\text { Capacidade } \\
\text { de moagem } \\
\text { (milhões } \\
\text { t/safra) }\end{array}$ & $\begin{array}{l}\text { Moagem } \\
\text { (milhões } \\
\text { de t) }\end{array}$ & $\underset{\text { (3) }}{\text { Part. }}(\%)$ & $\begin{array}{c}\text { Etanol } \\
\left(\mathrm{mil} \mathrm{m}_{(2)}^{3}\right)\end{array}$ & $\underset{(3)}{\text { Part. }}(\%)$ & $\begin{array}{l}\text { Açúcar } \\
(\text { mil t) }\end{array}$ & $\underset{(3)}{\text { Part. }}(\%)$ & $\begin{array}{c}\text { Bioeletricidade } \\
\text { comercializada } \\
(\mathrm{MW} / \mathrm{h})^{(2)}\end{array}$ \\
\hline & Brasil/ & & & & & & & & & \\
\hline Raízen & Holanda & 24 & 68,0 & 62,7 & 9,4 & $2.073,9$ & 6,9 & $4.177,7$ & 12,3 & 2.870 .000 \\
\hline Biosev (LDC) & França & 11 & 36,4 & 30,9 & 4,6 & $1.239,0$ & 4,1 & $1.705,0$ & 5,0 & 929.000 \\
\hline Odebrecht & Brasil & 9 & 36,0 & 29,2 & 4,4 & $1.943,4$ & 6,4 & 455,3 & 1,3 & 2.972 .685 \\
\hline São Martinho & Brasil & 4 & 23,0 & 22,3 & 3,4 & 943,7 & 3,1 & $1.229,7$ & 3,6 & 907.780 \\
\hline Bunge & EUA & 8 & 21,0 & 21,0 & 3,1 & $500,0 *$ & 1,7 & $1.500,0 *$ & 4,4 & 570.043 \\
\hline Tereos & França & 7 & 23,0 & 19,6 & 2,9 & 678,0 & 2,2 & $1.444,0$ & 4,3 & 1.400 .000 \\
\hline Santa Terezinha & Brasil & 9 & 22,0 & 17,9 & 2,7 & 445,9 & 1,5 & $1.689,4$ & 5,0 & 380.000 \\
\hline Coruripe & Brasil & 5 & 13,6 & 14,1 & 2,1 & 483,4 & 1,6 & 740,4 & 2,2 & 411.168 \\
\hline Lincon Junqueira & Brasil & 5 & 16,0 & 13,5 & 2,0 & 352,2 & 1,2 & $1.165,5$ & 3,4 & 174.700 \\
\hline CofcoAgri & China & 4 & 15,0 & 11,0 & 1,6 & 280,0 & 0,9 & 900,0 & 2,7 & N.I. \\
\hline Zilor & Brasil & 3 & 12,0 & 10,8 & 1,6 & 502,5 & 1,7 & 494,3 & 1,5 & 547.940 \\
\hline Clealco & Brasil & 3 & 11,0 & 9,9 & 1,5 & $295,1 * *$ & - & $626,6 * *$ & - & $108.807 * *$ \\
\hline Renuka do Brasil & Índia & 4 & 10,0 & 9,8 & 1,5 & 440,0 & 1,5 & 366,8 & 1,1 & 302.904 \\
\hline Moreno & Brasil & 3 & 11,0 & 9,5 & 1,4 & 517,5 & 1,7 & 334,1 & 1,0 & N.I. \\
\hline Delta Sucroenergia & Brasil & 3 & 10,0 & 9,1 & 1,4 & 289,5 & 1,0 & 702,2 & 2,1 & 147.197 \\
\hline Brasil & & 379 & - & 666,8 & 100,0 & $30.232,0$ & 100,0 & $\mathbf{3 3 . 8 3 7 , 0}$ & 100,0 & - \\
\hline
\end{tabular}

Observações: * Estimativa a partir de reportagens do NOVACANA (2017a).

**Dado referente à safra 2014/2015 devido a NRP (Unidade não respondeu a pesquisa para a safra 2015/2016)

Fonte: ${ }^{(1)}$ NOVACANA (2017a), ${ }^{(2)}$ INFOCANA (2017), ${ }^{(3)}$ UNICADATA (2016)

Organização: SANTOS, Henrique F.

Façanha (2012) afirma que no caso das operações joint-ventures, uma das modalidades de investimento mais praticadas no setor, além de compartilhar investimentos, riscos e lucros com a produção de açúcar, etanol e bioeletricidade, as empresas envolvidas também tem como objetivo a cooperação em áreas específicas, especialmente na logística, comercialização e tecnologia. Com isso, as empresas que se encontram menos estruturadas, em termos de capital, produtividade e logística, acabam se fragilizando frente à essa nova dinâmica competitiva de mercado, tornando-se alvo de F\&A ou até mesmo da falência. Segundo Macêdo (2011) 
A partir das operações de F\&A realizadas após 1999, o setor tem passado por um processo de profissionalização da sua gestão, resultando em estruturas administrativas mais eficientes. Dessa forma, as usinas que não acompanharem esse processo perderão competitividade, com grande possibilidade de serem adquiridas por outros grupos (MACÊDO, 2011, p. 58).

Assim, o processo de centralização do capital sucroenergético tem resultando, como consequência, no aumento da concentração do processamento de cana-de-açúcar e produção de açúcar e etanol entre alguns grupos nacionais e transnacionais. Segundo Macêdo (2011), na safra 2004/2005, os dez maiores grupos sucroenergéticos respondiam por $23,8 \%$ dos 386,09 milhões de toneladas de cana moída no Brasil e por 30,9\% e 26,3\% das produções totais de açúcar e etanol, respectivamente. Na safra 2011/2012, estes responderam por 27\% do total da cana moída, 29\% da produção de açúcar e $24 \%$ da produção de etanol (BARBOSA, 2013). Já na safra 2015/2016, foram responsáveis por aproximadamente $36 \%$ da moagem de cana, 44\% da produção de açúcar e $29 \%$ da produção de etanol (INFOCANA, 2017) (Gráfico $3)$.

Gráfico 3 - Brasil: participação dos dez maiores grupos do setor sucroenergético na moagem total de cana-deaçúcar e produção nacional de açúcar e etanol, safras 2004/2005, 2011/2012 e 2014/2015

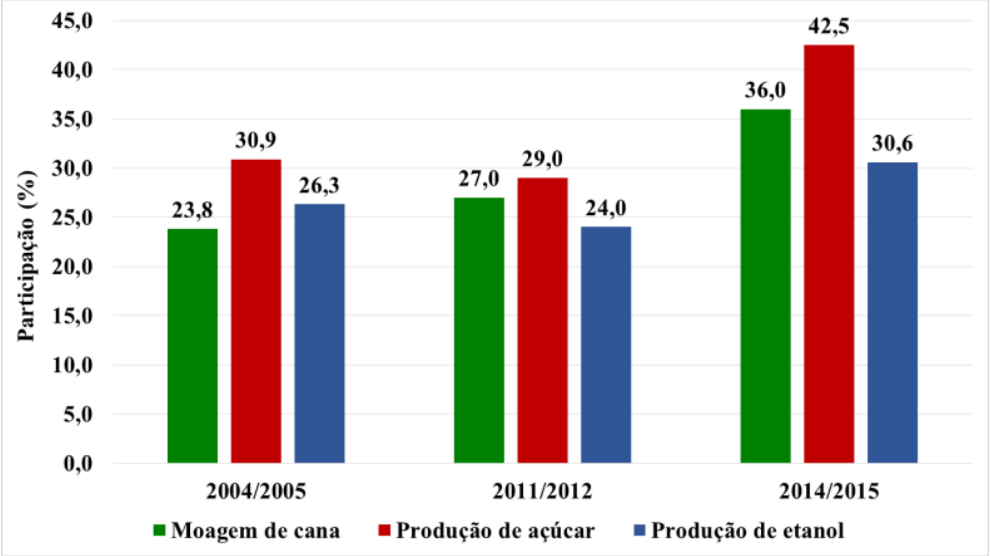

Organização: do autor a partir de Macedo (2011), Barbosa (2013) e Procana (2015)

Em relação à distribuição/comercialização do açúcar e do etanol, observa-se o predomínio de grandes tradings nacionais e estrangeiras, que inclusive participam diretamente na produção dos mesmos, como Copersucar, LDC, Bunge, Tereos, CoofcoAgri, Sojitz Corporation, Indofood, etc. Segundo Barbosa (2013), a estratégia destas empresas é fundamentalmente garantir o acesso aos produtos e reduzir o poder de barganha de fornecedores, bem como ter maior controle sobre os estoques e preços do mercado. Um dado que demonstra tamanha concentração é o de vendas do etanol hidratado no mercado interno. De acordo com a ANP (2016), a participação das dez maiores distribuidoras de combustível 
nas vendas do produto no Brasil elevou-se de 65,4\%, em 2000, para 81,4\% em 2015 (gráfico 4), enquanto que neste último ano as outras 130 distribuidoras do país participaram em apenas 18,4\% das vendas. Atualmente, somente as três maiores distribuidoras de combustíveis do país (Petrobrás, Ipiranga e Raízen) concentram 59\% das vendas do etanol hidratado (Gráfico 5), número que em 2000 era 32,3\%.

Gráfico 4 - Brasil: evolução da participação das dez maiores distribuidoras de combustível nas vendas nacionais de etanol hidratado, 2000-2015

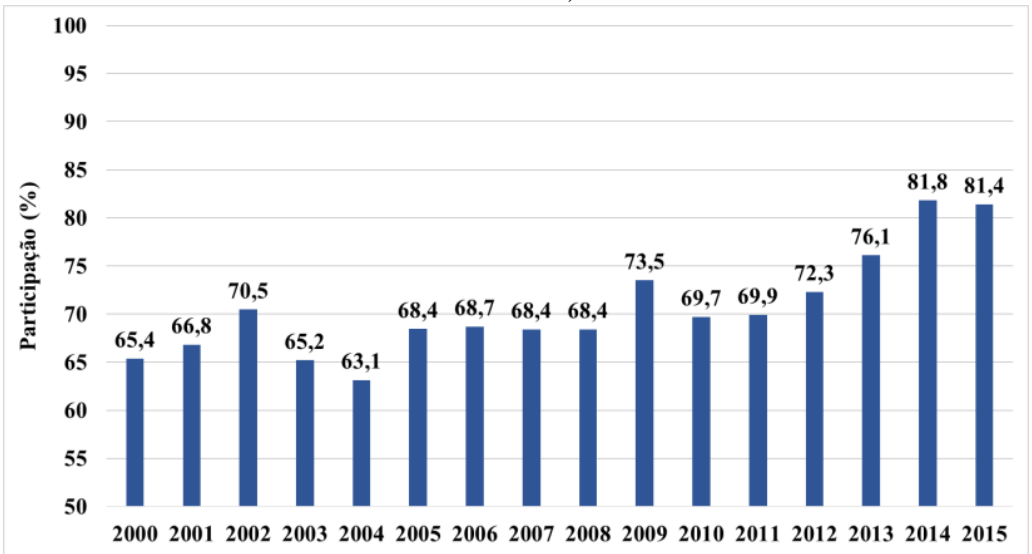

Fonte: ANP (2001-2016). Organização: SANTOS, Henrique F.

Gráfico 5 - Brasil: participação das dez maiores distribuidoras de combustível nas vendas nacionais de etanol hidratado, 2015

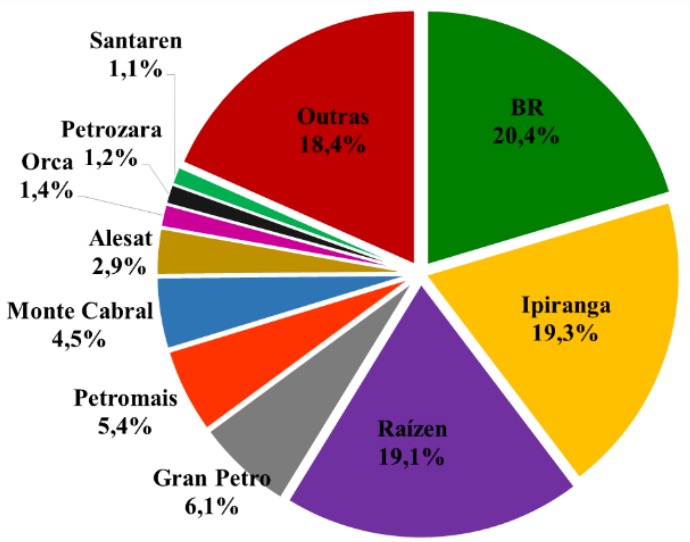

Fonte: ANP (2016). Organização: SANTOS, Henrique F.

Algo semelhante ocorre com as exportações de açúcar e etanol. Neste caso, é notória a ocorrência de associações entre grandes tradings mundiais para elevar o controle do mercado. A Cooperativa de Produtores de Cana-de-Açúcar, Açúcar e Álcool do Estado de São Paulo (Copersucar S/A), por exemplo, é hoje a maior trading nacional do setor sucroenergético. A cooperativa conta com mais de 85 UAS parceiras (35 sócias exclusivas e cerca de 50 não sócias) para produção e entrega das mercadorias. Juntas correspondem a aproximadamente $20 \%$ da moagem nacional de cana (COPERSUCAR, 2016). Para aumentar sua participação 
no mercado internacional, em 2012 a Copersucar adquiriu o controle da Eco-Energy, uma das tradings de biocombustíveis dos EUA. Juntas assumiram a liderança na comercialização de etanol e passaram a controlar mais de $12 \%$ do mercado mundial (ECO-ENERGY, 2016). Já em 2014 realizou uma joint-venture com a Cargill, formando uma nova empresa global de comercialização de açúcar (bruto a granel e branco) denominada de Alvean Sugar SL, o que resultou no controle de cerca de $30 \%$ da comercialização da commodity (ALVEAN, 2016).

Os recentes negócios da Copersucar refletiram diretamente no domínio do mercado brasileiro, tanto na produção quanto na comercialização. Do total do açúcar produzido no Brasil na safra 2015/2016 (33,8 milhões de toneladas), 31\% foram comercializados pela Copersucar e pela Alvean (10,5 milhões de toneladas). Já no total de açúcar exportado no país (24,6 milhões de toneladas), $34 \%$ do volume foram comercializados pelas duas empresas $(8,6$ milhões). Na mesma safra, a Copersucar também comercializou 17\% do total de etanol produzido no país (30,2 bilhões de litros) e exportou 28\% (0,6 bilhões de litros) do total do combustível nacional destinado ao exterior (2,1 bilhões) (UNICADATA, 2016; COPERSUCAR, 2016).

Seguindo o mesmo caminho, a Raízen Energia S/A tem aumentado consideravelmente sua participação no comércio internacional, sobretudo no de açúcar. Em 2016 a empresa realizou uma joint-venture com a empresa cingapuriana Wilmar International, formando a empresa RaW, que será encarregada de comercializar toda a produção de açúcar da Raízen destinada à exportação. Segundo o Novacana (2016), estima-se que a RaW deva responder por aproximadamente $20 \%$ de todas as exportações brasileiras de açúcar VHP (principal tipo de açúcar exportado no país). Em se tratando do etanol, a Raízen é hoje uma das principais produtoras e distribuidoras do produto no mercado interno brasileiro. Comercializado em mais de 5.700 postos de serviços com a marca Shell, o grupo garantiu um controle de 19,1\% do total das vendas do etanol hidratado em 2015 (ANP, 2016).

Além das associações com grandes tradings transnacionais, essas duas empresas também praticam uma outra estratégia de acesso e domínio do mercado de açúcar e etanol no Brasil: o controle direto de infraestruturas logísticas e/ou a participação acionária em grandes operadores logísticos. A Copersucar, por exemplo, detém o controle de um terminal açucareiro no porto de Santos, dois terminais multimodais de açúcar e um terminal de etanol ${ }^{4}$,

\footnotetext{
${ }^{4}$ A Copersucar S/A detém o Terminal Açucareiro Copersucar (TAC), localizado no porto de Santos (SP), com capacidade de expedição de 10 milhões de toneladas de açúcar por ano; dois terminais multimodais de açúcar, situados em Ribeirão Preto/SP e São José do Rio Preto/SP, com capacidade de movimentar 2 milhões de toneladas de açúcar por ano; e o Terminal Copersucar de Etanol (TCE), em Paulínia/SP, 
além de possuir 21,4\% das ações da Logum S/A, principal iniciativa logística para o etanol no Brasil (COPERSUCAR, 2016). A mesma estratégia é adotada pelo grupo Raízen, que detém uma gigantesca estrutura logística constituída de 63 terminais de distribuição de etanol e participação em 21,4\% das ações da Logum, 46,5\% da Uniduto Logística (que por sua vez controla 10,7\% das ações da Logum) e 28,4\% da Rumo (via Cosan Logística, um dos braços da Raízen) (RAÍZEN, 2016).

Se considerarmos, portanto, a participação dessas duas empresas (que sozinhas podem concentrar mais da metade das exportações brasileiras de açúcar) e de mais outras três grandes tradings que atuam no setor sucroenergético brasileiro atualmente - a LDC (que detém mais de $70 \%$ das ações da Biosev, segunda maior processadora global de cana-deaçúcar), a Tereos (que detém 60\% do Grupo Guarani, quarto maior produtor do setor) e a Bunge (quinto maior grupo do setor, com 8 UAS) - é evidente que tanto a produção quanto a distribuição/comercialização do etanol e do açúcar estão sendo gradativamente sujeitas a um oligopólio liderado por esses grandes agentes econômicos. Para Silveira (2010) as consequências deste tipo de mercado leva ao maior controle do território, culminando na perda da soberania econômica.

[...] a tendência às fusões empresariais reduz o número de polos decisórios, concentra ainda mais os vetores de mando e torna mais rígidas as relações entre áreas polarizadoras e áreas polarizadas. Dessa forma, como a fusão de empresas tende a ampliar a presença de capitais e de firmas globais no território, aumentam ao mesmo tempo os desequilíbrios e as novas formas de manifestação do setor externo da economia, em detrimento do setor interno (SILVEIRA, 2010, p. 79).

Desta forma, para atuar hegemonicamente no mercado e, portanto, manter o uso estratégico e corporativo do território (SANTOS; SILVEIRA, 2001), além de controlar boa parte da produção agrícola e agroindustrial, esses grandes grupos buscam efetivar o monopólio da maior parte das infraestruturas de armazenamento e transporte da região Centro-Sul destinadas à movimentação de etanol e açúcar, segmento chave do circuito espacial produtivo do setor sucroenergético, seja pela forma direta ou pela associação/cooperação (inclusive com participação acionária) com outros grupos de operação logística.

integrado ao etanoldutos da Logum e com capacidade de armazenar 180 milhões de litros de etanol (COPERSUCAR, 2016). 


\section{FINANCEIRIZAÇÃO E COMPETITIVIDADE NO SETOR SUCROENERGÉTICO}

O movimento de centralização e concentração de capital no setor sucroenergético ocorre apoiado em outro recente processo que vem se desdobrando de forma muito intensa no setor nos últimos anos: o de financeirização. Este processo pode ser resumido em três aspectos básicos: 1) crescente dependência do setor ao crédito (agrícola e agroindustrial) para custeio, investimento e comercialização junto a bancos (sobretudo pelo BNDES) (BORGES; COSTA, 2011) e outras instituições financeiras; 2) abertura do capital em Bolsa de Valores pelos grupos do setor ou participação majoritária destes em cotas acionárias de outros grupos com capital aberto em bolsa; 3) submissão da governança corporativa ao mercado financeiro (holdings, cotação da commodity açúcar, enxugamento de custos, formas de captação de recursos, etc.).

A financeirização se tornou primordial à competitividade do setor sucroenergético, pois segundo Pitta (2016), os altos custos com as operações agrícolas e agroindustriais, bem como de novos investimentos em implantação, ampliação e/ou modernização técnicoadministrativa depende cada vez mais de crédito (de preferência subsidiado pelo governo) e, consequentemente, de endividamento de médio e longo prazo. A captação de crédito junto ao mercado é feita de diversas formas (bancos, F\&A com grupos nacionais, transnacionais e fundos de investimentos, abertura de capital em bolsa de valores, mercado futuro de mercadorias), sendo fundamentalmente utilizada como estratégia de expansão dos grandes grupos do setor.

A captação eficiente de crédito é viabilizada por meio de esquemas financeiros que são cada vez mais utilizados pelas empresas envolvidas no setor sucroenergético e no agronegócio em geral, garantindo o que Pitta (2016) denominou de reprodução fictícia do capital canavieiro (ou esquema de "rolagem de dívidas"). Segundo o autor, novos empréstimos são contraídos sistematicamente para o pagamento de dívidas anteriores realizadas pelas empresas, o que mantém um "constante endividamento" e demanda incessante por somas de dinheiro e/ou operações financeiras rentáveis para suplantar a alta alavancagem. Nesses casos, segundo Pitta (2016), é recorrente a aquisição de mais crédito pelas empresas junto às instituições financeiras, ofertando como garantia de pagamento a produção futura de açúcar e etanol (penhora) e/ou ativos da empresa, como terras e maquinários (hipoteca). Todavia, vários mecanismos de especulação são praticados por esses 
grupos para "inflacionar ficticiamente" suas mercadorias e ativos (via mercado futuro e capital a juros), aumentando assim o montante de crédito captado no sistema financeiro.

Sobre o primeiro aspecto da financeirização, Spadotto (2016) mostra que entre 2000 e 2014 houve um aumento exponencial do crédito do BNDES destinado ao setor sucroenergético, de aproximadamente $\mathrm{R} \$ 0,4$ bilhões para $\mathrm{R} \$ 7,2$ bilhões (em 2016 caiu para próximo de R\$2,0 bilhões, segundo o BNDES, 2017). Boa parte dessas remessas foi para financiar, inclusive, operações de F\&A, por meio da linha de financiamento "mercado de capitais". Portanto, o Estado brasileiro, mediante pacto pela economia do agronegócio (DELGADO, 2012) e por intermédio do BNDES, tem sido fundamental no recente ciclo de expansão da agroindústria canavieira, capacitando financeiramente os agentes do setor para abertura de novas UAS, ampliação e modernização das existentes, incorporação de novas terras e realização de operações de compra e recompra de ações e títulos (PITTA et al., 2014).

A abertura de capital de grandes grupos na Bolsa de Valores também permite maior capitalização desses agentes, com acesso a diversas formas de crédito para expansão, conforme explicam Pitta et al. (2014, p. 9):

A abertura de capital de uma empresa também funciona como uma capitalização, ou seja, como promessa de produção futura de mercadorias, que retroalimentam a subida dos preços das ações da empresa e fomentam nova promessa de expansão. Não é só o capital financeiro investido nas ações das empresas que permite a expansão, mas o capital financeiro de empréstimo ou o chamado mercado de capitais. Uma empresa com capital em bolsa acessa créditos sobre os valores de suas ações, o que estimula sua expansão.

Em 2005, a Cosan S/A (uma das partes da Raízen Energia S/A) foi a primeira empresa do agronegócio brasileiro a abrir seu capital na Bolsa de Valores, Mercadorias e Futuro de São Paulo (BM\&FBovespa), o que permitiu que essa se torna-se, depois da joint-venture com a Shell, o maior grupo do setor sucroenergético brasileiro ${ }^{5}$. Outras empresas do setor também já seguiram o mesmo caminho: São Martinho S/A (2007), Tereos International (2010), Biosev S/A (2013), Raízen Energia S/A (2013) e Centro de Tecnologia Canavieira - CTC (2016). O caso deste último tornou-se muito interessante pelo fato de que o processo de financeirização do setor sucroenergético não se restringir apenas aos segmentos da produção e logística, mas

\footnotetext{
${ }^{5}$ Conforme Pitta (2016, p. 127), "a necessidade de continuar a se expandir para acessar novas dívidas, após a crise de 2007/2008, com a queda no preço do açúcar em dólares e a subida do dólar em relação ao real, levou à sua fusão [a Cosan S/A] com a Shell. Por esta ter acontecido, ou seja, por lograr acessar novos endividamentos e rolar os anteriores, a Raízen S/A não apareceu ao mercado como um dos grupos a falir, mas sim como um dentre os poucos que parecem se reproduzir."

Santos $2018 \quad$ ISSN 0104-5490 
também se expande para o segmento de PD\&I. Tendo forte participação acionária na CTC, os grandes líderes produtivos do setor ${ }^{6}$ possuem enormes expectativas de alavancar ganhos futuros com novas tecnologias desenvolvidas por essa instituição de pesquisa, que a partir dessa nova condição, poderá obter ainda mais recursos para financiar suas atividades.

Para Pitta et al. (2014, p. 11), “a abertura de capital é um patamar de financeirização qualitativamente diferenciado para uma empresa. Neste mercado, suas ações podem ser negociadas independentemente de sua produção de mercadorias". Sendo assim, as empresas de capital aberto e com grande capacidade de captação de recursos possuem melhores condições de acompanharem a evolução do mercado sucroenergético (sobretudo do que diz respeito à modernização técnico-científica e aos momentos de forte oscilação dos preços internacionais), financiar suas atividades via alto patamar de endividamento e, de certa forma, se manterem mais competitivas no mercado.

Outro indicador de financeirização do setor sucroenergético é a presença de fundos de investimentos no âmbito produtivo. Entre 2006 e 2008, alguns fundos entraram no setor por meio de F\&A, joint-ventures e/ou construção de novas UAS, como a Clean Energy Brazil (CEB), CNAA (Companhia Nacional de Açúcar e Álcool), Infinity Bio-Energy, Brenco (Brazilian Renewable Energy Company) e Vital Renewable Energy (VREC). No entanto, a crise de 2008 resultou em sucessivas desvalorizações financeiras desses fundos que, somado à redução dos preços do açúcar e etanol no mercado internacional e aos altos endividamentos realizados euforicamente para investimentos em expansão, levaram esses fundos a terem grandes prejuízos (PINTO, 2011). Tais fatos culminaram na saída da CEB, da CNAA (adquirida pela BP) e da Brenco (adquirida pela Odebrecht) do setor, enquanto a Infinity BioEnergy e a VREC embora tenham reduzido os seus investimentos, permaneceram produzindo no setor.

Outra questão importante é que a abertura de capital das grandes corporações em Bolsa de Valores favorece a participação de instituições e investidores financeiros (fundos de investimentos, fundos de pensão, fundos mútuos, sociedades de seguros, etc.) na estrutura acionária, o que dá a estes forte poder de influenciar e/ou conduzir as decisões e estratégias das companhias, segundo interesses puramente financeiros. Dentre essas estratégias, estão os novos investimentos e negócios que reduzam custos, aumentem a competitividade e maximizem os lucros da corporação, favorecendo a sua expansão e elevando o valor de suas

\footnotetext{
${ }^{6}$ As principais empresas acionárias do CTC são: Raízen Energia S/A (19,9\%), Copersucar S/A (17,7), BNDES Participações S/A (15,0\%), São Martinho Inova S/A (5,4\%), Odebrecht Agroindustrial Participações S/A $(4,6 \%)$ e Guarani S/A (Tereos Internacional) (4,0\%) (BM\&FBovespa, 2016). 
ações e títulos. A busca de oportunidades em novos ramos/setores e as operações de F\&A com/de outras empresas menos eficientes no mercado é uma das ações que permitem valorizar os ativos da companhia (o que dá a elas maior capacidade de adquirir crédito e reinvestir na expansão!), via diversificação de negócios e eliminação de concorrência.

No atual cenário econômico, a lógica financeira tem prevalecido cada vez mais sobre a governança corporativa das empresas, com o objetivo central de sempre maximizar o valor dos ativos para melhor remunerar os seus acionistas (LAZONICK; O'SULLIVAN, 2000). Segundo Macêdo (2011),

A Governança Corporativa se apresenta como uma maneira dos acionistas terem maior controle sobre as ações dos gestores das suas empresas, sendo um importante instrumento capaz de minimizar ou mesmo impedir que os CEOs tomem decisões que não reflitam o interesse dos acionistas. Algumas estratégias são utilizadas para manter os gestores focados nos objetivos dos proprietários das empresas (MACEDO, 2011, p. 54-55).

Um exemplo dessa lógica pode ser encontrado nas principais ações estratégicas e vantagens competitivas adotadas pela Biosev para atrair novos investidores, que podem ser verificadas no site da empresa. Dentre elas, estão: i) aumentar a produtividade e a eficiência agrícola e agroindustrial via modernização, qualificação e sistematização das operações; ii) maximização da rentabilidade através do aproveitamento de vantagens mais rentáveis do mercado em termos de produção, comercialização e consumo, identificadas a partir de uma plataforma privilegiada de informações a nível global adotada pela Louis Dreyfus Company (LDC), aproveitando inclusive a flexibilidade da produção de açúcar e etanol e de produtos com maior valor agregado; iii) disciplina financeira, através da redução de custos e despesas, otimização das necessidades do capital de giro, seletividade dos investimentos, alongamento dos endividamentos e redução da alavancagem financeira. Dentre as vantagens competitivas da companhia estão: i) plataforma de ativos (UAS localizados em ótimas regiões, armazéns, acesso ao sistema logístico); ii) escala de produção (segunda maior processadora de cana no mundo); iii) experiência com commodities da $L D C$, que possui eficiente controle de riscos e acesso a informações estratégicas sobre os mercados agrícolas globais; iv) inteligência comercial diferenciada, através do acesso e gestão destas informações (BIOSEV, 2016).

Segundo Lazonick; O’Sullivan (2000), as mudanças na financeirização das grandes corporações representam a transição de estratégias do tipo "reter e reinvestir", típicas do período fordista, para estratégias do tipo "racionalizar e distribuir", adequada ao novo regime 
de acumulação flexível (HARVEY, 2010) e assentada no conceito de maximização do shareholder value como forma ideal de governança corporativa. Harvey (2011b, p. 169) afirma que "a ascensão das finanças e dos serviços financeiros teve como paralelo uma notável mudança na remuneração das corporações financeiras, bem como a tendência, entre corporações maiores, de fundir as duas funções". No dizer de Chesnais (2005), as grandes empresas transnacionais industriais tornaram-se, na verdade, centros financeiros com atividades industriais. A subordinação das estratégias corporativas pelas financias proporcionam, segundo o autor, o processo de acumulação financeira ${ }^{7}$.

Já Braga (1997), afirma que "a financeirização é o padrão sistêmico de riqueza", onde a riqueza gerada pelas financias tem sido muito superior ao da riqueza gerada pela produção e comércio de bens e serviços (riqueza real), dado a constante valorização do capital fictício. Para Chesnais (2005), a valorização improdutiva do capital é uma realidade cada vez mais comum no plano estratégico das grandes empresas, na medida em que estas adotam diversos mecanismos para gerar lucros sem realizar produção, como a especulação de ações e títulos, investimentos monetários e venda de serviços. Tal conjuntura é muito emblemática quando analisamos a "inflação fictícia" dos ativos, operada pelos grupos sucroenergéticos através de diversos mecanismos de especulação, para a maior captação de recursos possíveis no mercado, como forma de sustentar os seus elevados endividamentos ${ }^{8}$, conforme discute Pitta (2016).

\section{CONSIDERAÇÕES FINAIS}

Considerando as fontes alternativas de energia como ramo estratégico para economia mundial, o etanol combustível é visto como uma ótima oportunidade de investimento para garantir o contínuo processo de acumulação de capital pelas grandes corporações contemporâneas. $\mathrm{O}$ açúcar, que é uma commodity, também participa nesse mercado, visto o expressivo aumento do seu consumo e a sua valorização ao longo dos últimos anos.

Como os dados puderam demonstrar, o grande número de operações de F\&A nas duas últimas décadas sugere a entrada de grandes corporações capitalizadas e financeirizadas e a

\footnotetext{
${ }^{7}$ Por acumulação financeira, entende-se a centralização em instituições especializadas de lucros industriais não reinvestidos e de rendas não consumidas, que têm por encargo valorizá-los sob a forma de aplicação em ativos financeiros - divisas, obrigações e ações - mantendo-os fora da produção de bens e serviços (CHESNAIS, 2005, p. 37).

${ }^{8}$ De acordo com a reportagem do Estadão (2018), as empresas do setor sucroenergético totalizam um patamar de endividamento estimado em aproximadamente $\mathrm{R} \$ 100$ bilhões. 
eliminação de empresas menos competitivas no setor sucroenergético, culminando em concentração e centralização do capital. Com isso, é notória a ocorrência de oligopolização tanto da produção quanto da comercialização/distribuição do açúcar e etanol no mercado, o que incide em ganho de poder dos grandes grupos para manipular a oferta e os preços desses produtos conforme interesses puramente financeiros dos mesmos, podendo acarretar em prejuízos ao consumidor final (haja vista os sucessivos aumentos após 2015 nos preços dos combustíveis, atendendo de forma particular as empresas do setor).

Nas regiões produtivas canavieiras, tal estrutura de mercado se organiza geralmente através de clusters, que conforme demonstrou Bellantani (2015), oportuniza a subordinação dos proprietários de terras e produtores de cana-de-açúcar. Estando algumas UAS de um mesmo grupo sucroenergético localizadas relativamente próximas geograficamente, ocorre um processo de "monopolização do território" (OLIVEIRA, 2016), já que todos os fornecedores de terras e da matéria-prima acabam tendo que negociar com uma mesma empresa 9 . Outro fato é a remuneração da matéria-prima baseada na quantidade de Açúcar Total Recuperável (ATR), sistema criado pelo Conselho dos Produtores de Cana-de-Açúcar, Açúcar e Etanol do Estado de São Paulo (CONSECANA) e que de certa forma favorece a grande submissão dos produtores às UAS. O cálculo do preço e a quantidade medida de ATR é realizado pela agroindústria ${ }^{10}$. Ambos os aspectos oportuniza a eliminação do ambiente de livre negociação dos agricultores.

A maior presença das corporações e do mercado financeiro, bem como a busca incessante por competitividade, sinalizam maior controle do território pelos agentes do agronegócio (CASTILLO, 2013). Isto, porém, ignora ou elimina qualquer fato, processo ou situação econômica, social ou ambiental, que possa dificultar ou impedir a livre circulação do capital, agravando tradicionais problemas do setor canavieiro associados à expropriação camponesa e de comunidades tradicionais, à grilagem, à concentração fundiária e à degradação ambiental (MARTINELLI; FILOSO, 2008; SZMRECSÁNYI; GONÇALVES, 2009).

\footnotetext{
${ }^{9}$ Isso muito se deve também às características intrínsecas do setor sucroenergético (CASTILLO, 2013), como a restrição no armazenamento da matéria-prima e a semiperenidade da cultura, que exigem que o cultivo da cana-de-açúcar se localize em um raio médio de $40 \mathrm{Km}$ no entorno das UAS.

${ }^{10}$ Xavier; Pitta; Mendonça (2011, p. 23) destacam, por exemplo, que no sistema remuneratório baseado no ATR, normalmente os cálculos não são divulgados aos fornecedores e que os preços geralmente caem justamente no período da colheita e fornecimento para as UAS. 


\section{REFERENCIAS}

ANP - Agência Nacional de Petróleo, Gás Natural e Biocombustíveis. Anuário Estatístico Brasileiro do Petróleo, Gás Natural e Biocombustíveis (2001 a 2015). Rio de Janeiro: ANP, 2016.

BARBOSA, A. P. F. P. L. Mudança nos grupos estratégicos da indústria sucroalcooleira brasileira. Dissertação (Mestrado em Ciências). 78f. São Paulo: FEAC/USP, 2013.

BELLENTANI, N. F. A territorialização dos monopólios no setor sucroenergético. Tese (Doutorado em Geografia). 176f. São Paulo: FFLECH-USP, 2015.

BM\&FBovespa - Bolsa de Valores, Mercadorias e Futuros de São Paulo. Empresas listadas. 2016. Disponível em: 〈http://www.bmfbovespa.com.br〉. Acesso em: outubro/2016.

BORGES, A. C. G.; COSTA, V. M. H. de M. Distribuição dos desembolsos do BNDES no setor sucroenergético no Brasil. Estudos Geográficos, v. 9, n. 2, jul./dez. 2011, p. 73-88.

BRAGA, J. C. S. Financeirização Global. In: TAVARES, M. C.; FIORI, J. L. Poder e Dinheiro. Rio de Janeiro: Vozes, 1997, p. 212-242.

CASTILLO, R. A expansão do setor sucroenergético no Brasil. In: BERNARDES, J. A.; SILVA, C. A.; ARRUZZO, R. C. (Org.). Espaço e energia: mudanças no paradigma sucroenergético. Rio de Janeiro: Lamparina, 2013, p. 75-84.

CGEE (Centro de Gestão e Estudos Estratégicos). Bioetanol de cana-de-açúcar: uma oportunidade para o Brasil. Brasília: CGEE, 2009.

CHESNAIS, F. A finança mundializada. São Paulo: Boitempo Editorial, 2005.

DELGADO. G. Do capital financeiro na agricultura à economia do agronegócio: mudanças cíclicas em meio século (1965-2012). Porto Alegre: Editora da UFRGS, 2012.

DORNELLES, R. de G. Etanol - políticas públicas, histórico e desafios. In: BERNARDES, J. A.; SILVA, C. A.; ARRUZZO, R. C. (Org.). Espaço e energia: mudanças no paradigma sucroenergético. Rio de Janeiro: Lamparina, 2013, p. 42-50.

EPE. Empresa de Pesquisa Energética. Análise de conjuntura dos biocombustíveis: ano 2016. Disponível em: <www.epe.gov.br>. Acesso em junho/2017.

ESTADÃO. Com dívida de $\mathbf{R} \mathbf{\$} 100$ bi, usinas apostam em etanol para tentar se recuperar. Reportagem, 22/01/2018. Disponível em:〈https://goo.gl/rEbo9m>. Acesso em: janeiro/2018.

FAÇANHA, S. L. de O. Aquisições, fusões e alianças estratégicas na cadeia sucroenergética brasileira. Tese (Doutorado em Ciências) 339f. São Paulo: USP, 2012.

HARVEY, D. O enigma do capital e as crises do capitalismo. São Paulo: Boitempo, 2011a.

HARVEY, D. (2005). O Neoliberalismo: história e implicações. 2 ed. São Paulo: Edições Loyola, $2011 \mathrm{~b}$.

HARVEY, D. (1989) Condição pós-moderna. 20 ed. São Paulo: edições Loyola, 2010.

HIRST, P.; THOMPSON, G. Globalização em questão: a economia internacional e as possibilidades de governabilidade. Petrópolis: Vozes, 1998.

INFOCANA. Portal da Infocana. 2017. Disponível em:<https://www.infocana.com.br>. Acesso em: fevereiro/2017. 
KPMG. Fusões e Aquisições 2016 - $1^{\circ}$ Semestre. São Paulo: KPMG, maio/2016. Disponível em: 〈https://home.kpmg.com/br/pt/home/insights〉. Acesso em: outubro/2016.

LAZONICK, W.; O'SULLIVAN, M. Maximizin shareholder value: a new ideology for corporate governance. Economy and Society, vol. 29, n.1, 2000, p. 13-35.

MAPA. Ministério da Agricultura, Pecuária e Abastecimento. Anuário Estatístico da Agroenergia 2014. Secretaria de Produção e Agroenergia. Brasília: MAPA/ACS, 2015.

MARTINELLI, L. A.; FILOSO, S. Expansion of sugarcane ethanol production in Brazil: environmental and social challenges. Ecological Applications, 18(4), 2008, p. 885-989.

MARX, K. O Capital. Livro Primeiro, vol. II. Rio de Janeiro: Civilização Brasileira, 1980.

MACÊDO, F. dos S. A reestruturação do setor sucroenergético no Brasil: uma análise do período entre 2005 e 2011. Dissertação (Mestrado em Agroenergia). 71f. São Paulo: EESP/FGV, 2011.

MENDONÇA, M. L.; PITTA, F. T.; XAVIER, C. V. A agroindústria canavieira e a crise econômica mundial. São Paulo: Outras Expressões, 2012.

NEVES, M. F.; CONEJERO, M. A. Estratégias para a cana no Brasil: um negócio classe mundial. São Paulo: Atlas, 2010.

NOVACANA. Notícias do Portal NovaCana. 2016. Disponível em:<https://www.novacana.com/n>. Acesso em: outubro/2016.

NOVACANA. RaW eleva concentração na exportação de açúcar; embarcará $20 \%$ do VHP do Brasil. 2016. Disponível em: 〈https://goo.gl/ppe1Gh>. Acesso em: outubro/2016.

OLIVEIRA, A. U. A. Mundialização da Agricultura Brasileira. São Paulo: Iandé Editorial, 2016.

PINHEIRO, J. C. Análise da Dinâmica das Áreas Ocupadas Pela Cultura Canavieira no Brasil entre 1990 e 2013: uma contribuição ao estudo do circuito espacial produtivo do setor sucroenergético. Dissertação (Mestrado em Geografia). 173f. Campinas: IG/UNICAMP, 2015 .

PINTO, M. J. A. Investimentos diretos estrangeiros no setor sucroenergético. Dissertação (Mestrado em Administração de Organizações). 171f. Ribeirão Preto: FEAC/USP, 2011.

PITTA, F. T. As transformações na reprodução fictícia do capital na agroindústria canavieira paulista: do Proálcool à crise de 2008. Tese (Doutorado em Geografia). 420f. São Paulo: FFLECH/USP, 2016.

PITTA, F. T.; XAVIER, C. V.; NAVARRO, C.; MENDONÇA, M. L. Empresas transnacionais e produção de agrocombustíveis no Brasil. São Paulo: Outras Expressões, 2014.

PROCANA. Anuário da Cana: Brazilian Sugar and Etanol Guide. 2016. Ribeirão Preto: PROCANA, 2017.

REN21. Renewable Energy Policy Network for the 21st Century. Renewables 2015 Global Status Report. REN21, 2015. Disponível em: <http://www.ren21.net>. Acesso em: junho/2016.

SANTOS, M.; SILVEIRA, M. L. (2001) O Brasil: território e sociedade no início do século XXI. $13^{\circ}$ ed. São Paulo: Record, 2010. 
SZMRECSÁNYI, T.; GONÇALVES, D. B. Efeitos Socioeconômicos e Ambientais da Expansão da Lavoura Canavieira no Brasil. In: XXVIII CONGRESSO DA ASSOCIAÇÃO DE ESTUDOS LATINO-AMERICANOS. Rio de Janeiro: LASA, 2009.

SPADOTTO, B. R. Centralização do capital e especialização territorial: o setor sucroenergético e o mercado de trabalho em Piracicaba (SP). Dissertação (Mestrado em Geografia). 124f. Campinas: IG/UNICAMP, 2016.

UNICADATA. Dados da União da Industria de Cana-de-açúcar. Portal UNICA. 2016. Disponível em:<http://www.unicadata.com.br>. Acesso em: outubro/2016. 